\title{
MANAJEMEN PEMBELAJARAN BLENDED LEARNING DALAM UPAYA MENINGKATKAN EFEKTIVITAS BELAJAR MAHASISWA
}

\author{
OLEH: \\ MUHAMMAD SOLEH HAPUDIN \\ (AKADEMI TELKOM JAKARTA)
}

\begin{abstract}
The development of the 21 st century world is marked by the use of information and communication technology in all facets of life. Utilization of Information Communication and Technology (ICT) through the internet in all fields, including in the education or learning process. Progress in the world of ICT changes many things, in the world of work that can be replaced by advances in the world of Internet technology of Thing (IoT) and Artificial Intelligence (AI). Lecturers must have the ability to adapt to changes and technological development by changing the learning process so far the lecture is not only face-to-face, but can be done online in order to improve education access services. Internet as a result of technological developments certainly has an influence in the world of education, especially in the learning process that has changed conventional learning patterns into modern patterns based online with the use of Information Communication and Technology (ICT), known as E-Learning.

Collaborative learning between conventional learning and ICT-based learning developed as collaborative learning or known as Blended Learning. In the management of Blended Learning learning is very effective, Blended Learning Learning is very effective to use because it provides easy accessibility of students wherever, whenever and wherever can be accessed in accordance with the required learning outcomes. Blended Learning learning resources are not fixated on lecturers in the course but can be from various sources, in the form of digital, video and other sources of information.
\end{abstract}

\section{Keywords: Learning, Internet, Blended learning, E-Learning}

\section{PENDAHULUAN}

Revolusi Industri 4.0 atau dikenal juga Fourt Industrial Revolution yang merupakan era industry keempat sejak revolusi industry pertama pada abad ke-18. Era Revolusi Industri ditandai dengan perpaduan teknologi yang mengaburkan batas antara bidang fisik, digital dan bilogis, secara kolektif disebut sebagai sistem siber fisik (cyber physical System/CPS). Revolusi Industri 4.0 akan benar-benar mengubah cara hidup dan bekerja saat ini kedatangan era ini dipicu oleh data dan 
perangkat terhubung internet yang mampu mengumpulkan dan memproses aliran informasi (Savitri, 2019:179)

Perkembangan Teknologi komputer membawa banyak perubahan pada dunia pendidikan, khususnya dalam pembelajaran.aktivitas pembelajaran semakin maksimal dengan keberadaan teknologi komputer yang dikombinasikan dengan internet, terlebih saat ini hamper semua masyarakat modern sudah tidak sing lagi dengan internet. Dengan kemajuan tersebut mendorong lembaga pendidikan memanfaatkan sistem e-learning untuk meningkatkan efektivitas dan fleksibilitas pembelajaran. Dari beberapa hasil penelitian menunjukan bahwa efektifitas dalam pembelajaran yang menggunakan sistem e-Learning cenderung sama bila di bandingkan dengan pembelajaran sistem klasikal atau tatap muka. Keunggulan yang diperoleh dari sistem pembelajaran E-Learning. E-Learning merupakan bagian dari pembelajaran jarak jauh, sedangkan pembelajaran on-line adalah bagian dari e-learning. Sementara itu, pembelajaran on-line adalah bagian dari pembelajaran berbasis teknologi yang memanfaatkan sumber daya internet, intra net. mekanisme pembelajaran E-Learning materi pembelajaran bisa lakukan dimana, kapan dan dari mana saja. Selain itu materi pembelajaran dapat diperkaya dari berbagai sumber belajar yang lain.

Tujuan pemanfaatan teknologi komputer dalam pendidikan antara lain sebagai berikut; Pertama, menyadarkan mahasiswa untuk beradaptasi terhadap perkembangan teknologi komputer yang terus berkembang, sehingga mahasiwa dapat termotivasi untuk terus belajar sepanjang hayat. Kedua, mengembangkan kompetenai mahasiswa dalam menggunakan teknologi computer untuk mendukung proses pembelajran dan berbagai aktivitas dalam kehidupan seharihari. Ketiga, mengembangkan kemampuan belajar secara mandiri mandiri (self regulated learning),inisiatif, inovatif, kreatif dan bertanggungjawab dalam penggunaan teknologi informasi. Pembelajar mandiri berarti mahasiswa memiliki kesadaran akan pentingnya belajar di manapun dan kapanpun ia berada, dimana hal ini merupakan sarana untuk mengembangkan bakat dan potensi dan meraih prestasi. Pembelajar mandiri memiliki makna tidak tergantung lagi tenaga pendidik, lingkungan materi dan lain-lain. Dengan perkembangan teknologi 
informasi dosen dapat memberikan layanan tanpa harus bersifat langsung dengan mahasiswa. Demikian pula mahasiswa dapat memperoleh informasi melalui on line atau ruang maya.

Dampak kemajuan teknologi informasi tersebut, dunia pendidikan harus adafftif dan merespon sesuai dengan tuntutan global yang mencerminkan keterbukaan, kompetitif, dengan inovasi yang cepat sehingga mengubah proses pembelajaran yang selama ini dilakukan kuliah tidak hanya tatap muka, namun bisa dilakukan pembelajaran secara onlinestilah ini dikenal dengan E-Learning.

E-Learning atau pembelajaran daring (online) merupakan salah satu bagian pendidikan Jarak Jauh yang secara khusus merupakan kombinsai teknologi elektronika dan memanfaatkan teknologi internet serta pemograman yang memungkinkan mahasiswa untuk berinteraksi dengan bahan-bahan perkuliahan melalui chat room sedangkan pembelajaran on-line merupakan bagian dari $E$ Learning. Sistem Pembelajaran saat ini tidak terbatas pada tatap muka namun dilakukan pula secara online atau virtual yang di kenal Blended Learning. Blended learning yang berasal dari bahasa Inggris, yang terdiri dari dua suku kata, blended dan learning. Blended memiliki makna kombinasi atau campuran. Learning (belajar). Istilah lain yang sering digunakan hybrid course (hybrid=campuran/kombinasi, course $=$ mata kuliah). Blended Learning ini pada dasarnya merupakan gabungan keunggulan pembelajaran yang dilakukan secara tatap-muka dan secara online atau virtual. Dengan memanfaatkan ICT, dosen dapat berinteraksi dan berkomunikasi dengan mahasiswa/siswa, atau antar dan antara mahasiswa/siswa, atau berbagi sumber-sumber belajar yang dapat terjadi kapan saja dan di mana saja tanpa dibatasi oleh ruang waktu, selama saling terkoneksi dalam sistem jaringan komputer melalui internet.

Blended Learning ini merupakan sistem perpaduan pembelajran antara pembelajaran berbasis virtual dan pembelajaran konvensional, maka pembelajaran ini dapat diterapkan pada mata kuliah apa pun, termasuk mata Matematika yang salah satunya dipengaruhi oleh perkembangan ilmu pengetahun dan teknologi yang pesat. 


\section{LITERATURE REVIEW}

Perkembangan teknologi computer telah membawa banyak perubahan pada dunia pendidikan, khusunta dalam proses pembelajaran. Aktivitas pembelajaran semakin maksimal dengan keberadaan teknologi computer yang dikombinasikan dengan fasilitas internet, hal yang mencerminkan keterbukaan, kompetitif, dengan perubahan yang cepat sehingga mengubah proses pembelajaran yang selama ini dilakukan kuliah tidak hanya berhadapan, namun bisa dilakukan pembelajaran secara daring istilah ini dikenal dengan E-Learning.

E-Learning merupakan salah satu bagian pendidikan Jarak Jauh yang secara khusus menggabungkan teknologi elektronika dan memanfaatkan teknologi internet serta pemograman yang memungkinkan mahasiswa untuk berinteraksi dengan bahan-bahan pelajaran melalu chat room (ruang komunikasi), sedangkan pembelajaran on-line merupakan bagian dari E-Learning. E-Learning meliputi berbagai aplikasi dan proses, seperti computer based learning, web based learning, dan lain-lain. sementara itu, pembelajaran on-line adalah bagian dari pembelajaran berbasis teknologi yang memanfaatkan sumber daya internet. Dengan demikian, e-learning merupakan media pemanfaatan teknologi internet untuk mendistribusikan materi pembelajaran sehingga mahasiswa dapat mengakses dimana saja dan kapan saja.

Menurut Darin E Hartley (2001) dalam Muhamad Rusli (2017:75) mengatakan E-Learning merupakan suatu jenis belajar yang memungkinkan tersampaikannya bahan ajar ke peserta didik dengan mengginakan media internet, intranet atau media jaringan computer lain. Namun dengan kemajuan teknologi saat ini sistem Pembelajaran tidak terbatas pada tatap muka namun dilakukan pula secara online atau virtual yang di kenal Blended Learning.

Blended learning yang berasal dari bahasa Inggris, yang terdiri dari dua suku kata, blended dan learning. Blended memiliki makna kombinasi atau campuran. Sedangkan Learning (belajar). Istilah lain yang sering digunakan Hybrid Course (hybrid=campuran/kombinasi, course=mata kuliah). Bersin (2004) dalam Wasis (2018:59) mendefinisikan blended learning sebagai berikut: 
Adapun teori belajar yang relevan dan mendukung pelaksanaan ELearning yaitu, teori kontrsuktivisme yang beranggapan bahwa pengetahuan adalah hasil kontruksi manusia. Manusia mengkonstruksi pengetahuannya melalui interaksi dengan objek, fenomena, pengalaman dan lingkungan mereka.

Teori belajar Piaget sebagai kontruktivis menegaskan bahwa pengetahuan yang dibangun dalam pikiran anak, bukan semata-mata diperoleh secara pasif oleh seseorang. Tetapi hal tersebut telah disesuaikan dengan tingkat perkembangan intelektual dan pengalaman berpikirnya, dan diwujudkan melalui tindakan. (Deni Darmawan, 2014:52).

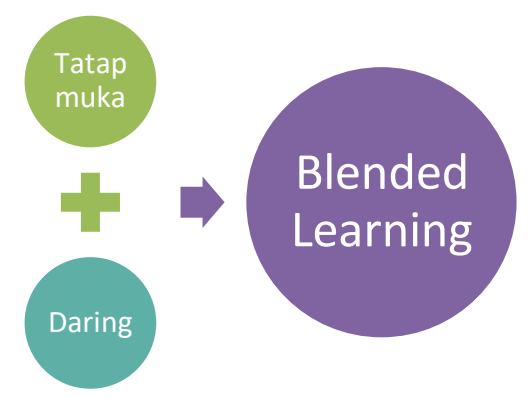

Gambar 4.1 Blended Learning

Blended Learning ini pada dasarnya merupakan sebuah kombinasi pembelajaran yang dilakukan secara tatap-muka dan secara online atau virtual. Kegiatan pembelajaran konvensional bersifat tatap muka (face to face) tidak boleh diabaikan, sehingga pembelajaran dalam Blended Learning menjadikan pembelajaran akan efektif serta bermakna.

Kelebihan Blended learning:

1. Tenaga pendidik dapat memberikan materi pembelajaran dapat feksibilitas waktu kapan saja, dimana saja dan tempat untuk mengakses mata kuliah

2. Peserta didik atau mahasiswa dapat bahan perkuliahan secara mandiri dengan bahan ajar yang telah dikirim dan di simpan secara on line.

3. Seandainya materi belum dapat dipahami, mahasiswa dapat melakukan diskusi dengan dosen baik secara daring dialog interaktif diwaktu-waktu tertentu ataupun off line.

4. Pembelajaran yang dilakukan memiliki fleksibilitas

Dalam Blended learning selain memiliki kelebihan, tentu juga memiliki keterbatasan, keterbatasan pada blended learning yaitu : 
1. Kesiapan tenaga pendidik memiliki keterampilan dalam E-Learning

2. Kesiapan tenaga pendidik menyiapkan dan mengembangkan materi pembelajaran, menyiapkan sistem penilaian, menjawab dan memberikan umpan balik dalam forum yang di sampaikan oleh mahasiswa

3. ketidakmerataan fasilitas pendukung dan tingkat penguasaan teknologi

Menurut Kamarga (2002) dalam Deni Darmawan (2014:34) mengatakan manfaat

E Learning dalam organisasi belajar antara lain:

1. Meningkatkan produktivitas

2. Mempercepat proses inovasi

3. Efisiensi

4. Flexible dan interaktif

Menurut Deni darmawan (2014:64) mengatakan bahwa dalam proses penyelenggaraan E-Learning dibutuhkan LMS (Learning Management System). LMS dikenal sebagai CMS (Course Management System).

Jason Cole (2005) dalam Deni darmawan (2014:65) mengatakan, secara umum fungsi-fungsi yang harus terdapat dalam LMS/CMS antara lain :

1. Uploading and sharing material

2. Forum and chat

3. Quizzes and surveys

4. Gathering and reviewing assignment

5. Recording grade

\section{RESEARCH METHOD}

Pendekatan dan metode penelitian yang di gunakan dalam penelitian ini adalah pendekatan kualitatif. Metode yang digunakan adalah metode deskriptif, sehingga penelitian ini di arahkan untuk mendeskripsikan dan menganalisa Manajemen Pembelajaran Blended Learning dalam meningkatkan efektivitas pembelajaran. Deskripsi dan analisis dilakukan berdasarkan temuan-temuan dan peristiwa, proses dan hasil. Adapun teknik yang digunakan dalam mendapatkan data yakni menggunakan teknik wawancara, obervasi dan studi dokumentasi, catatan lapangan dan studi pustaka. Data yang terkumpul dideskripsikan dan dianalisis sampai pada kesimpulan, melalui reduksi data 


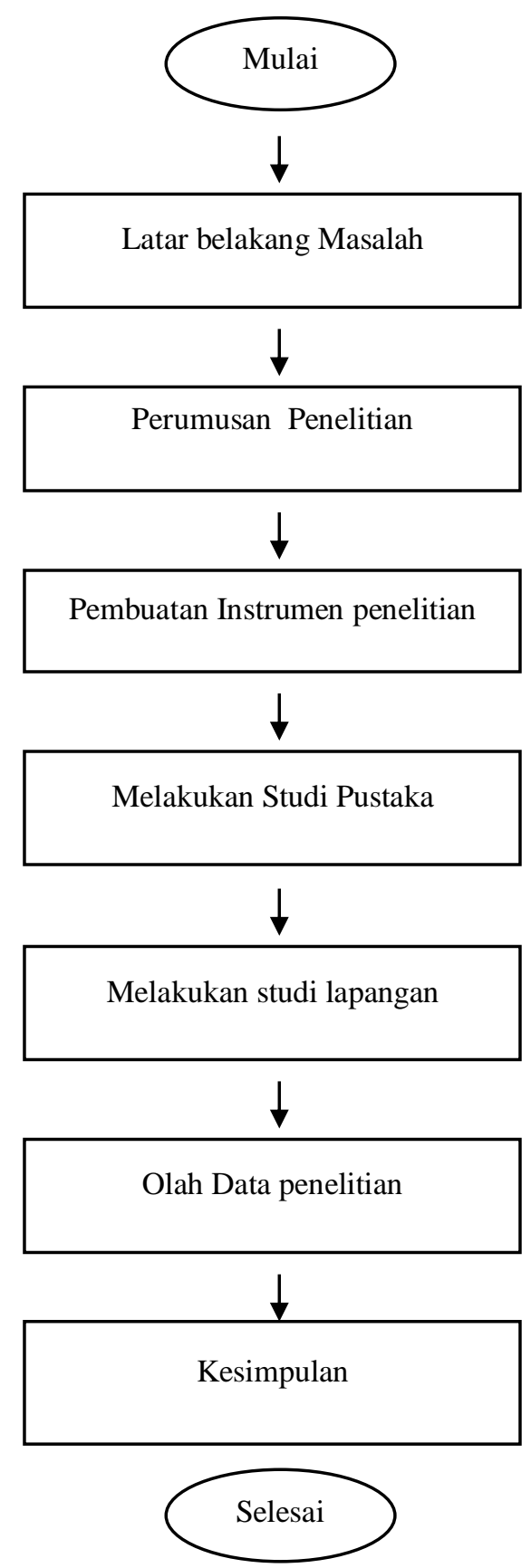

Gambar 3.1 Tahapan-tahapan Penelitian

Tahapan - tahapan pada Gambar 3.1 akan dijelaskan secara rinci pada penulisan dibawah ini:
a. Latar belakang
b. Perumusan penelitian
c. Pembuatan instrument penelitian 
d. Melakukan studi pustaka

e. Melakukan studi lapangan

f. Olah data penelitian

g. kesimpulan

\section{RESUlts AND DisCUSSION}

Penelitian bahwa Blended Learning lebih efektif dibandingkan dengan sistem pembelajaran konvensional dengan sistem tatap muka dibandingkan dengan sistem virtual. Tingkat efektifitas tersebut ditunjang dengan kelebihan pola pembelajaran Blended Learning. Keuntungan Blended learning:

1. Dosen dapat menyampaikan materi pembelajaran dapat feksibilitas waktu kapan saja, dimana saja sesusi kesempatan yang dimiliki.

2. Mahasiswa dapat belajar secara mandiri

3. Pembelajaran yang dilakukan memiliki keluwesan

Adapun kekurangan pembelajaran Blended Learning.

1. Kesiapan dosen dalam menyiapkan dan mengembangkan materi pembelajaran

2. Kesiapan dosen memiliki keterampilan dalam E-learning.

a. Perencanaan pembelajaran Blended Leaning

Dalam merencanakan pembelajaran blended learning ketua program studi, mengarahkan kepada pengampu mata kuliah untuk mengajar sesuai Rencana Pembelajaran Semester (RPS) mata kuliah, dan dosen untuk mengirimkan bahan kuliah kepada tim pengelola Blended Learning yang bertugas untuk mengupload, dan melakukan administrasi blended Learning. Sebelum perkuliahan dimulai diadakan pertemuan sebanyak 2 kali yang pertama terkait dengan Pelatihan penggunaan e-Learning pertemuan kedua informasi aturan akademik, aturan nilai, presensi dan lain-lain.

\section{b. Pelaksanaan pembelajaran Blended Learning}

Dalam rangka memberikan kemudahan serta pemerataan pendidikan yang bemutu kepada masyarakat, Sistem Pendidikan Jarak Jauh (PJJ) sebagai sebuah solusi dalam menghadapi, dimana saja dan kapan saja. yang menggunakan fasilitas Sesuai Unadng-Undang No 12 Tahuin 2012 tentang Pendidikan Tinggi dalam 
pelaksanaan Blended Learning perkuliahan dilakukan sesuai dengan aturan akademis, bahwa perkuliahan dilakukan sebanyak 16 kali pertemuan, yang terdiri dari 3 kali tatap muka (2 kali sebelum UTS) dan 1 kali pertemuan sebelum UAS. Pertemuan On line (11 kali pertemuan) pada satu semester. Sebelum pelaksanaan blended learning berlangsung dosen yang mengajar pada semester berjalan, untuk menyerahkan bahan perkuliahan ke tim Pusat Bahan Ajar E-Learning (PBAL) agar materi dapat di upload web E-Learning. Bahan telah di upload dapat diakses oleh seluruh mahasiswa, disertai dengan forum dan Quiz atau project. Untuk presensi kehadiran mahasiswa ditentukan oleh pengisian Forum, Quiz dan download materi. Semakin aktif bertanya dalam forum dan quiz berisi soal. Forum tersebut dosen memberikan tugas besar mata kuliah yang diberikan pada saat UTS atau UAS, sehingga mahasiswa dituntut kemandiran dalam perkuliahan.

\section{c. PengorganisasianmPembelajaran Blended Learning}

Pembelajaran Blended learning di ampu oleh dosen matakuliah yang telah ditugaskan oleh Ketua program studi. Adapun mata kuliah yang akan di on line kan ditentukan oleh Pusat Bahan Ajar E-Learning (PBAL) yang memiliki tugas dan fungsi dalam pengaturan blended learning, termasuk kalender akademik, asistensi, penilaian kinerja dosen, dan pengaturan jadwal ujian dan lain-lain. Program Studi berfungsi sebagai pengawas kinerja dosen, pengumpulan penilaian mahasiswa.

\section{d. Pengawasan Pembelajaran Blended Learning.}

Pengawasan pelaksanaan pembelajaran dilakukan 2 (dua) pengawasan internal, yakni Pengawasan Pusat Bahan Ajar E-Learning (PBAL) terhadap aktivitas dosen dan pengawasan Dosen terhadap presensi mahasiswa. Mekanisme pengawasan terhadap dosen dilakukan melalui kehadiran mahasiswa dengan metode penilaian, meliputi : download materi yang di upload oleh dosen pengampu, aktifitas forum diskusi oleh mahasiswa, dan pengisian quiz oleh mahasiswa. Adapun presensi asistensi yang diabsen secara manual dilakukan sebelum UTS dan sebelum UAS. Fungsi Pengawasan yang dilakukan langsung Pusat Bahan Ajar E-Learning (PBAL) Blended Learning terhadap Dosen, dilakukan melalui sistem, baik itu kehadiran dosen bisa dilakukan pengawasan melalui keaktifan dosen dalam 
merespon tanggapan dari mahasiswa, adapun program studi terkait dengan jumlah kehadiran melalui tatap muka maupun on line, dan asistensi dosen pengampu mata kuliah di wajibkan hadir sebagai sarana memfasilitasi sera pendalaman materi bagi mahasiswa. Apabila ada keluhan dan masukan mahasiswa disampaikan kepada ketua program studi masing-masing.

\section{e. Efektivitas pembelajaran Bleanded Learning}

Penyelenggara pembelajaran Blended Learning dilakukan dalam upaya memberikan aksesibilitas mahasiswa agar bisa mengikuti perkuliahan secara tatap muka dan secara virtual atau on line, hal ini dalam rangka memberikan aksesibilitas pembelajaran kepada mahasiswa kapan, dimanapun berada bisa mengikuti perkuliahan. Dosen dalam melihat hasil pembelajran disetiap bahan materi perkuliahaan quiz sebagai assessment terhadap penguasaan materi tersebut. Untuk menjaga mutu proses pembelajaran Blended Learning, upaya yang dilakukan Pusat Bahan Ajar E-Learning (PBAL) adalah melakukan monitoring kesesuain Rencana Pengajaran Semester (RPS) dengan materio perkuliaan yang dilakukan oleh dosen pengampu mata kuliah dengan penugasan. Dalam pembelajaran Blended Learning seorang dosen harus memiliki perubahan peranan dan menempatkan diri sebagai orang yang mengarahkan dan memberi petunjuk mempelajari secara mandiri dengan berbagai sumber belajar yang ada. Manajemen proses pembelajaran blended learning mahasiswa tidak terpaku pada satu sumber belajar, namun memiliki beberapa sumber informasi yang bersifat digital, yang dapat memperkaya ilmu pengetahuan yang dapat diakses secara virtual. dan tugas serta fungsi dosen dalam pembelajaran blended learning mengarahkan mahasiswa agar mempelajari sumber informasi sesuai dengan topik bahasan

\section{PENUTUP}

Dari hasil temuan penelitian bahwa sistem pembelajaran blended learning dapat disimpulkan bahwa:

\section{a. Pelaksanaan}

Telah sesuai dengan Standar Nasional Pendidikan Tinggi (SNPT) dan Peraturan Pemerintah No. 109 Tahun 2013 tentang Penyelenggaraan Pendidikan Jarak Jauh 
pada Pendidikan Tingi pasal 4 bahwa penyelenggaraan perkuliaan yaitu 50\% (lima puluh perseratus) berbasis virtual, dan $50 \%$ mata kuliah tatap muka dalam 1 (satu) mata kuliah.

\section{b. Pengorganisasian}

kegiatan pembelajaran blended learning di kelola oleh lembaga yang bersifat independent yakni oleh Pusat Bahan Ajar E-Learning (PBAL) berkoordinasi dengan masing-masing Ketua program studi dalam pelaksanaan pembelajaran blended learning.

\section{c. Pelaksanaan}

pelaksanaan Blended Learning perkuliahan dilakukan sesuai dengan aturan akademis, bahwa perkuliahan dilakukan sebanyak 16 kali pertemuan, yang terdiri dari 3 kali tatap muka (2 kali sebelum UTS) dan 1 kali pertemuan sebelum UAS. Pertemuan On line (11 kali pertemuan) pada satu semester.

\section{d. Pengawasan}

Pengawasan pelaksanaan pembelajaran dilakukan 2 (dua) pengawasan internal, yakni Pengawasan Pusat Bahan Ajar E-Learning (PBAL) terhadap aktivitas dosen dan pengawasan Dosen terhadap presensi mahasiswa.

\section{e. Efektifitas pembelajaran}

Pembelajaran blended learning, sangat efektif digunakan karena memberikan kemudahan aksesibilitas mahasiswa dimanapun, kapan dan dimanapun dapat diakses. Sumber belajar bukan terpaku pada dosen pengampu mata kuliah tetapi dapat dari berbagai sumber, berupa sumber informasi yang bersifat digital, video maupun lainnya.

\section{DAFTAR PUSTAKA}

Daryanto dan Saiful Karim. (2017). Pembelajaran abad 21. Bandung: Gava Media

Darmawan, Deni (2014). Pengembangan E-Learning Teori dan Desain. Bandung:Rosdakarya

Ma'mur Asmani, Jamal, (2010). Tips Efektif Pemanfaatan Teknologi Informasi dan Komunikasi dalam dunia pendidikan. Jogjakarta: Diva Press. 
Ni Nyoman Parwati, dkk, (2018). Belajar dan Pembelajaran. Depok: Rajawali Press.

Priadi, Singgih, (2013). Model Blended Learning. Surakarta:Yuma Presindo.

PERMENDIKBUD RI No. 109 Tahun 2013 Tentang Penyelenggaraan Pendidikan Jarak Jauh Pendidikan Tinggi(PJJ).

PERMENDIKBUD RI No. 4 Tahun 2014 Tentang Penyelenggaraan Pendidikan Tinggi

Rusli, Muhammad (2017). Multimedia Pembelajaran yang Inovatif. Jogjakarta:Penerbit Andi.

Rusman, (2012). Model-Model Pembelajaran. Jakarta: Rajawali Press

Sanjaya, Wina dan Andi Budimansah (2015). Paradigma Baru Mengajar. Bandung:Kencana

UU No. 12 Tahun 2012 Tentang Pendidikan Tinggi.

(2013). Belajar dan Pembelajaran Berbasis Komputer. Bandung: Alfa Beta. 